\title{
Endothelial Denudation of Isolated Human Internal Mammary Artery Segments
}

Victor Lamin ${ }^{1}$, Michael Worthington², James Edwards², Fabiano Viana², Robert Stuklis ${ }^{2}$, David Wilson ${ }^{1}$ and John Beltrame $^{1^{*}}$

${ }^{1}$ Discipline of Medicine, School of Medicine, University of Adelaide and Cardiology Research Unit, Basil Hetzel Institute for Translational Health Research, The Queen Elizabeth Hospital, Australia

${ }^{2} D$ 'Arcy Sutherland Cardiothoracic Surgical Unit, Royal Adelaide Hospital North Terrace, Australia

\begin{abstract}
Background: Endothelial denudation is an important approach to evaluate the role of the endothelium in vascular reactivity studies. Although approaches to remove the endothelium are well established in animal models, these methods have proved difficult to effectively translate to remnants of human Internal Mammary Artery (IMA) obtained during coronary bypass. This study sought to identify the optimal technique for endothelial denudation of IMA while preserving vascular contractile responses.
\end{abstract}

Methods: IMA segments were subject to endothelial denudation using one of the following techniques: (1) surface abrasion, rubbing with a stainless steel wire, (2) vasoconstriction abrasion or (3) shear abrasion via infusion of an effervescent solution. Following intervention, IMA segments were evaluated by: (1) histochemistry to quantify structural damage and endothelial cell abundance and (2) functional endothelium-dependent vasodilator response using vascular myography in an organ bath preparation.

Results: Vasoconstriction abrasion removed endothelial cells and caused disruption of the internal elastic lamina, these vessels failed to respond to the vasoconstrictor Phenylephrine (PE) or the endothelium-dependent vasodilator A23187. Surface abrasion alone was incomplete in removing endothelial cells, vessel vasodilated partially when challenged with A23187 in the presence of PE. Shear abrasion removed endothelial cells most effectively, as these pre-constricted vessels did not relax to $\mathrm{A} 23187$ but demonstrated increased sensitivity to PE.

Conclusions: In this controlled comparative study assessing both structural and functional endpoints of endothelial denudation techniques, we have demonstrated that shear abrasion by infusion of an effervescent solution is the optimal technique to remove the endothelium and preserve vascular function in human IMA.

Keywords: Internal mammary artery; Endothelium denudation; Vascular reactivity

\section{Abbreviations}

IMA: Internal Mammary Artery; CABG: Coronary Artery Bypass Graft; PE: Phenylephrine; VIP: Vasoactive Intestinal Peptide; BMI: Body Mass Index; ACE-inhibitor: Angiotensin Converting Enzyme Inhibitor; SSRI: Selective Serotonin Reuptake Inhibitor; H\&E: Haematoxylin and Eosin

\section{Introduction}

The research carried out during the last 3 decades gave us deeper insight into our understanding of the complexity of the vascular endothelium. Previously perceived as an inert cellular lining, it is now appreciated as a complex endocrine organ regulating vascular function via the release of vasoactive autocoids as well as influencing platelet activity $[1,2]$. Vascular endothelial denudation leads to loss of endothelial function and a subsequent increase vascular sensitivity to vasoactive autocoids $[3,4]$. This has been a fundamental method to assess the role of the endothelium of an isolated vessel preparation in vascular reactivity studies. Previous vascular reactivity studies have denuded the vascular endothelium of isolated vessel via mechanical and chemical approaches. Chemical endothelial denudation through treatment with detergent $[5,6]$ is considered unsafe and has been found to compromise the viability of the smooth muscle cell [7].

Mechanical endothelial denudation has been undertaken in both animal and human isolated vessel via (1) the gentle rubbing of the luminal surface of the vessel with wooden stick [8], syringe needle [9], stainless steel wire [10,11], forcept [12], blunt seeker [13] and balloon catheter [14,15], (2) intense vascular constriction upon a intravascular rod [16] and (3) the passing of air bubbles through the lumen of the vessel [17]. Similar studies utilising the human internal mammary artery (IMA) have been problematic and met with variable success in achieving consistent endothelial denudation, since the vessel is not amenable to the above established denudation techniques.

The objective of this study is to determine the most effective endothelial denudation technique for IMA in isolated vessel preparations, as assessed by vascular reactivity studies.

\section{Methods}

Patients scheduled for elective Coronary Artery Bypass Grafting (CABG), were consented pre-operatively for the use of their discarded IMA vessel. The study was approved by the Royal Adelaide Hospital Human Ethics Committee. Standard cardiac surgical procedures were undertaken utilising a combination of opioid (fentanyl), inhalation

*Corresponding author: John F Beltrame, Professor of Medicine, Discipline of Medicine, School of Medicine, University of Adelaide, Basil Hetzel Institute for Translational Health Research, The Queen Elizabeth Hospital, 28 Woodville Road, Woodville SA, 5011, Australia, Tel: 6188222 6740; E-mail: john beltrame@adelaide.edu.au

Received April 14, 2016; Accepted May 06, 2016; Published May 10, 2016

Citation: Lamin V, Worthington M, Edwards J, Viana F, Stuklis R, et al. (2016) Endothelial Denudation of Isolated Human Internal Mammary Artery Segments. Cardiovasc Pharm Open Access 5: 180. doi:10.4172/2329-6607.1000180

Copyright: (c) 2016 Lamin V, et al. This is an open-access article distributed under the terms of the Creative Commons Attribution License, which permits unrestricted use, distribution, and reproduction in any medium, provided the original author and source are credited. 
(isoflorane) and muscle relaxant (rocuronium) in anaesthesia, followed by a primary median sternotomy approach.

The left IMA was harvested as a pedicle graft with the excess vessel length trimmed. The remnant IMA segment from the region prior to the bifurcation was available for the experimental studies before the treatment with papaverine.

\section{Vessel isolation}

The IMA segments were immediately placed into ice-cold Krebsbicarbonate solution containing in $\mathrm{mmol} / \mathrm{L}: \mathrm{NaCl} 118, \mathrm{KH}_{2} \mathrm{PO}_{4} 1.18$, $\mathrm{KCl} 3.89, \mathrm{NaHCO}_{3} 25, \mathrm{MgCl}_{2} 1.05, \mathrm{CaCl}_{2} 2.34$, EDTA 0.01 and glucose 5.56 at $\mathrm{pH} 7.4$, previously aerated with carbogen gas $\left(95 \% \mathrm{O}_{2}\right.$ and $5 \%$ $\mathrm{CO}_{2}$ ). Each vascular segment was dissected free of connective tissue and cut into $3 \mathrm{~mm}$ wide segments.

\section{Endothelial denudation techniques}

The IMA segments were assigned to either a control group (no endothelial denudation) or one of the following experimental luminal mechanical endothelial denudation approaches:

Surface abrasion method: This traditional approach involves mechanical removal of the endothelium by gentle rubbing of the intimal surface with stainless-steel wire as described previously by Wackenfors [10] and Aleksandar [11].

Constrictor abrasion method: In this technique, a stainless steel rod is inserted through the lumen of the vascular segment, ensuring that the rod occupies $\geq 90 \%$ of the vessel lumen. The vessel (with the rod insitu), is then immersed in high potassium (KPSS) solution containing in mmol/L: $\mathrm{KH}_{2} \mathrm{PO}_{4} 1.18, \mathrm{KCl} 16, \mathrm{NaHCO}_{3} 25, \mathrm{MgCl}_{2} 1.05, \mathrm{CaCl}_{2}$ 2.34, EDTA 0.01 and glucose 5.56 at $\mathrm{pH} 7.4$ ) previously aerated with Carbogen gas $\left(95 \% \mathrm{O}_{2}\right.$ and $\left.5 \% \mathrm{CO}_{2}\right)$ to induce vascular constriction upon the stainless steel rod. The rod was then carefully moved back and forth three times within the vessel lumen thereby removing the endothelium. This is a hybrid approach to similar methods that utilise an inflated balloon catheter rather than the stainless steel rod as described previously by $\mathrm{Lu}[16]$.

Shear abrasion method: This technique involves high velocity intraluminal infusion of an effervescent solution consisting of air and physiological Krebs solution through a catheter, moving the catheter tip within the lumen for 90 seconds as described previously by Guyton [17] with some modifications.

\section{Assessment of endothelial integrity}

Structural assessment: Control and experimental isolated IMA preparations were fixed in $10 \%$ buffered neutral formalin, embedded in paraffin before being sectioned transversely ( $5 \mu \mathrm{m}$ sections), and mounted on glass slides. Sections were immuno-stained for CD 34 and Haematoxylin and eosin (H\&E) for histological examination. The total number of CD 34 positive cells per view was estimated as the average number of cells in 20 views at different location. Images were captured using a Nikon Eclipse 90i microscope and recorded on a Nikon cool snap HQ camera.

Functional assessment: Vascular reactivity was assessed using vascular myography in an organ bath preparation with the isolated IMA segments mounted on stainless steel hooks and vessel tension measured with a force transducer. The organ bath preparation involved a $15 \mathrm{ml}$ jacketed organ bath containing Krebs solution bubbled with Carbogen. Isometric tension was recorded using Lab chat 6 software with the system being calibrated each day before the start of any experiment.
The vessel segments were allowed to stabilize at a resting tension of $19.6 \mathrm{mN}$ for 1 hour at $37^{\circ} \mathrm{C}$ before the experiments commenced. The vessels were submaximally contracted with KPSS solution three times, to confirm a functional vessel and optimize the vascular contractile apparatus function. Following a further 30 minute equilibration period, a cumulative dose response curve to the phenylephrine agonist (PE, 0.01 $\mu \mathrm{M}-300 \mu \mathrm{M})$ was generated and the dose producing a half maximal response determined. After the last response, vessel was allowed to equilibrate for 1 hour and pre-contracted to a dose of the agonist that produces $70 \%$ constriction. Upon reaching a plateau constrictor response, the endothelium-dependent vasodilator A23187 (a calcium ionophore, $2 \mu \mathrm{M}$ ), was added to confirm endothelial integrity.

\section{Data analysis}

Vascular constriction was expressed as change in weight per miliNewton $(\mathrm{mN})$ normalized with the KPSS response and relaxation responses as the percentage reduction in the agonist-induced constriction. Dose-response curve to PE constriction was obtained. Data are expressed as mean \pm SEM. Statistical analysis of paired data has been made using student t-test to compare and analyze the variance (ANOVA) of two or more than two groups. Differences are considered significant at $\mathrm{p}<0.05$.

\section{Results}

IMA segments were obtained from 15 patients $(60 \%$ male) with mean age: $68.0 \pm 13.25$ ) undergoing CABG. Patient characteristics are summarized in Table 1 . A total of 48 segments were studied with similar luminal diameters between the study groups. A total of 12 experimental conditions were undertaken per intervention.

\section{Structural assessment}

Histological examination of the control group revealed a continuous lining of endothelial cells, separated from the smooth muscle layer by an intact continuous internal elastic lamina (Figure 1). An intact internal elastic lamina was also evident in all the segments subjected to the mechanical shear abrasion method, suggesting intact sub-intimal layers despite denudation of the endothelial lining (Figure 1). IMA segments subjected to the mechanical surface abrasion method

\begin{tabular}{|c|c|}
\hline Total Patient & 15 \\
\hline Male & $60 \%$ \\
\hline Mean age & $68.0 \pm 13.25$ \\
\hline Vascular Risk Factors & $2(13 \%)$ \\
\hline Current smoker & $3(20 \%)$ \\
\hline Ex-smoker & $6(40 \%)$ \\
\hline Diabetic & $11(73 \%)$ \\
\hline Hypertensive & $8(53 \%)$ \\
\hline Hypercholesterolemia & $26.7 \pm 4.50$ \\
\hline BMI & $9(60 \%)$ \\
\hline Drug therapy & $13(86 \%)$ \\
\hline Anti-platelet & $11(73 \%)$ \\
\hline Statin & $6(40 \%)$ \\
\hline Beta-Blocker & $4(26 \%)$ \\
\hline ACE-Inhibitor & $2(13 \%)$ \\
\hline Calcium Channel Blocker & $5(33 \%)$ \\
\hline Nitrate & $2(13 \%)$ \\
\hline Diuretic & $4(26 \%)$ \\
\hline SSRI & \\
\hline Angiotensin Receptor Blocker & \\
\hline
\end{tabular}

Table 1: Patient characteristics and pre-operative medications for included patients. 
Citation: Lamin V, Worthington M, Edwards J, Viana F, Stuklis R, et al. (2016) Endothelial Denudation of Isolated Human Internal Mammary Artery Segments. Cardiovasc Pharm Open Access 5: 180. doi:10.4172/2329-6607.1000180
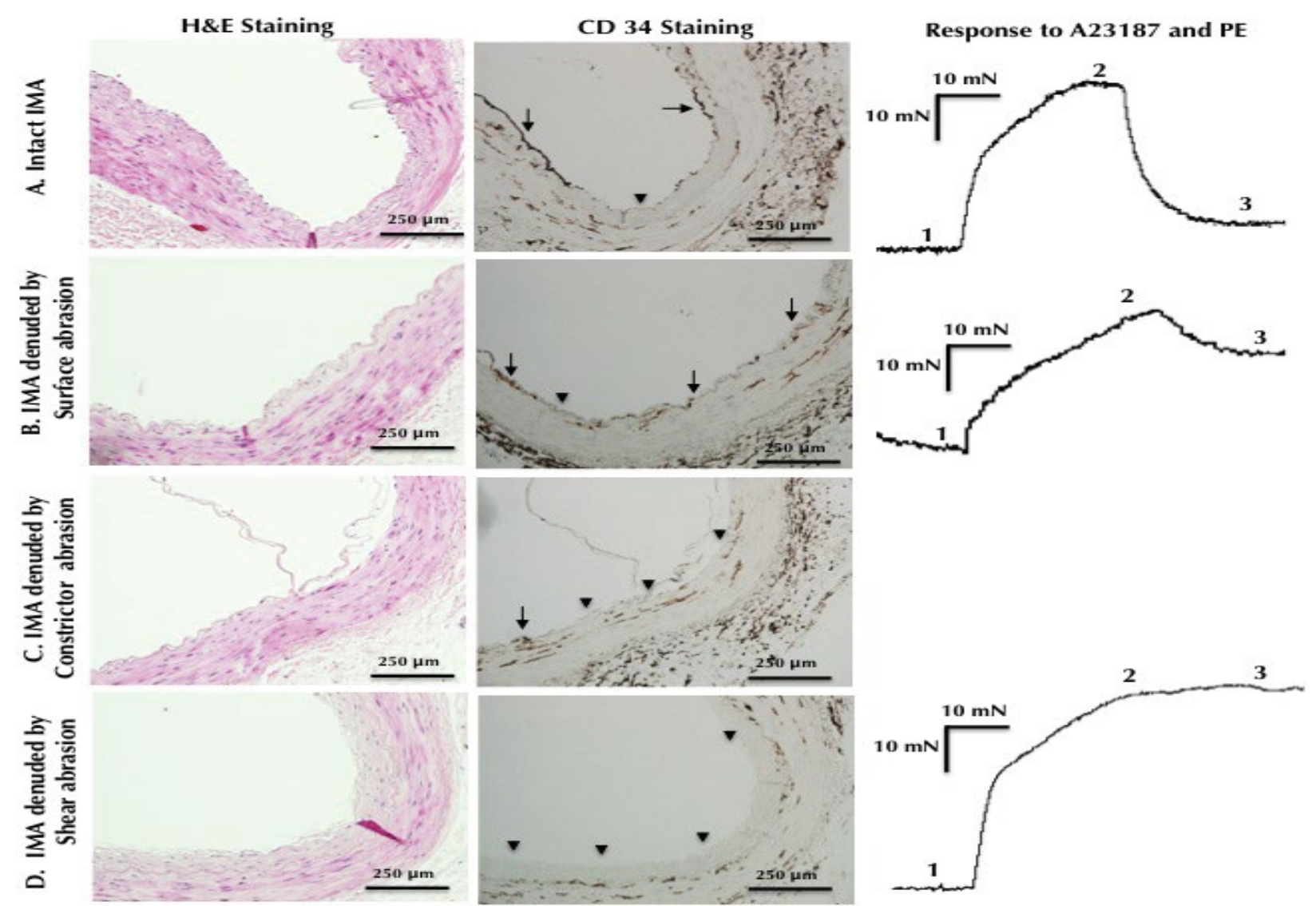

(A) Control segments with intact endothelial lining (H\&E and CD34 staining; black arrow indicates endothelial cell lining and arrowhead indicates denuded area) that are pre-constricted with PE (1) and exposed to an endothelium-dependent vasodilator (2) demonstrate a vasodilator response (3). (B) Surface abrasion produces endothelium removal, but there were still viable endothelial cells produces endothelium-dependent vasodilator response (C) Constriction abrasion produces distortion of the internal elastic lamina and vessel were unable to respond to PE or A23187 and (B) Shear abrasion produces significant removal of endothelial cells and hyperconstriction to PE with a loss of the endothelium-dependent vasodilator response.

Figure 1: Structural and functional findings from endothelial denudation of human IMA segments.

demonstrated variable amounts of distortion in the elastic lamina, which occasionally extended into the smooth muscle layer (Figure 1). In the mechanical constrictor abrasion method, there was substantial disruption in the elastic lamina, which extended into the smooth muscle layer. Endothelial denudation by shear abrasion demonstrated very few endothelial cells remaining within the luminal lining and minimal damage to the vascular smooth muscle cell layer. This was confirmed by quantification of the average number of $\mathrm{CD} 34$ positive cells per view (intact IMA $=13.15 \pm 6.3$, surface abrasion $\mathrm{IMA}=3.7 \pm$ 2.8 and shear abrasion $\mathrm{IMA}=1.6 \pm 1.4$, Figure 2 ). This suggests that endothelial denudation by the surface abrasion method was not as effective as the shear abrasion method.

\section{Functional assessment}

IMA denudation using surface and shear abrasion method has equivalent contraction responses to the potassium depolarising solution, whereas constriction abrasion has a reduced response compared to the intact IMA (Intact IMA: $27.3 \pm 17.8 \mathrm{mN}$, surface abrasion: $20.9 \pm 16.7 \mathrm{mN}$, constriction abrasion: $7.5 \pm 1.15 \mathrm{mN}$ and shear abrasion: $23.7 \pm 12.2 \mathrm{mN}$, Figure 3 ).

Vasoconstrictor responses to incremental PE concentrations produced concentration-dependent contractions in intact and denuded IMA segments. There was a significant difference in maximal endothelium dependent vascular relaxation to A23187 between control IMA $(84 \pm 2.0 \%)$, IMA subjected to surface abrasion $(29.43 \pm 1.5 \%)$ and shear abrasion $(0.04 \pm 0.3 \%)$.

There was no difference in the $\mathrm{EC}_{50}$ of the concentration-response curve of the surface abrasion (compared to intact vessel), indicating equal sensitivity to PE. However, there was a difference in the $\mathrm{EC}_{50}$ of the concentration-response curve of the mechanical shear abrasion denudation (compare to intact IMA), indicating that they are more sensitive to $P E$ than the intact IMA $\left(E_{50}\right.$ : intact vessel $=2.41 \pm 0.34 \mu \mathrm{M}$, surface abrasion $=2.07 \pm 1.33 \mu \mathrm{M}$, and shear abrasion $=1.29 \pm 0.34 \mu \mathrm{M}$, Figure 4).

\section{Discussion}

This study is the first comprehensive systematic evaluation of endothelial denudation techniques for the IMA. Using both structural and functional assessments, the study demonstrates that the shear abrasion technique is the optimal method for denuding the endothelium from isolated IMA segments obtained from patients undergoing elective CABG. Although there was no differences between intact IMA, surface and shear abrasion in response to the standard potassium depolarising stimulus, there was a trend of reduced responses in the surface abrasion suggesting that part of its smooth muscle cell apparatus was damaged. 


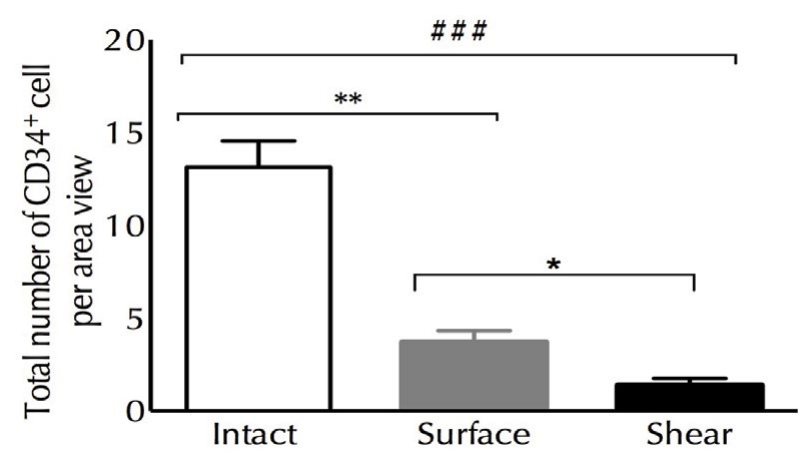

Shear abrasion leads to decrease endothelial cell number compared to intact IMA (intact IMA-white bar: $13.15 \pm 6.3 \mathrm{n}=12$, surface abrasion-grey bar: $3.7 \pm 2.8 n=6$ and shear abrasion-back bar: $1.6 \pm 1.4 n=12$ ). Results are presented as mean \pm standard error of the mean. ${ }^{*},{ }^{* *}$ and $\# p>0.05$.

Figure 2: Endothelial cell loss with denudation.

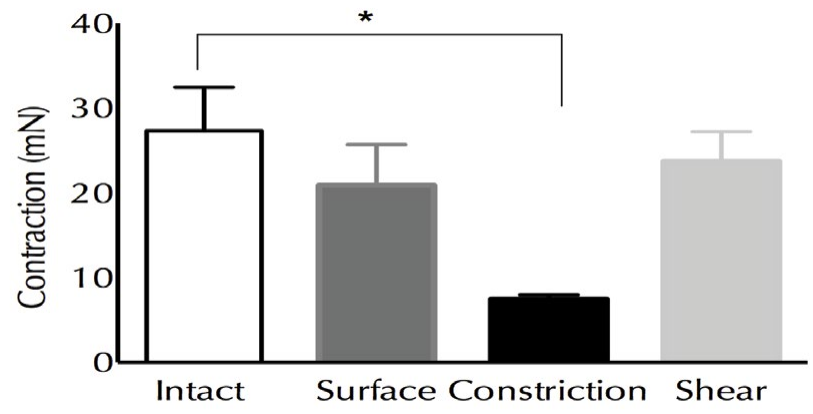

Shear abrasion has equal strength of contraction to potassium ion as compared to Intact IMA (Intact IMA-white bar: $27.3 \pm 17.8 \mathrm{mN}, \mathrm{n}=12$ ), surface abrasiondark grey bar: $20.9 \pm 16.7 \mathrm{mN}, \mathrm{n}=12$, shear abrasion-black bar: $23.7 \pm 12.2$ $\mathrm{mN}, \mathrm{n}=12$ ) and constriction abrasion-grey bar: $7.5 \pm 1.15 \mathrm{mN}, \mathrm{n}=6)$ ). Results are presented as mean \pm standard error of the mean, $p>0.05$

Figure 3: Contractile responses to potassium ion following mechanical denudation.

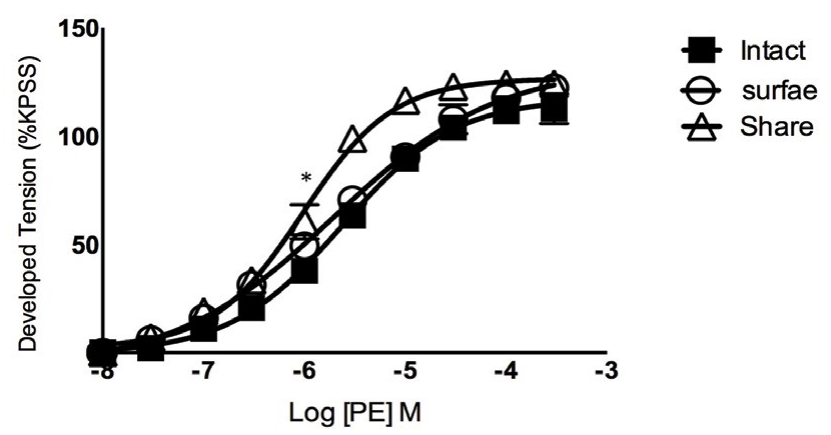

Mechanical shear abrasion increase vascular sensitivity to PE compared to the intact IMA (Intact IMA EC I0 $_{50}: 2.41 \pm 0.34, n=12$ close square, surface abrasion $\mathrm{EC}_{50}: 2.07 \pm 0.13, \mathrm{n}=6$ close circle and shear abrasion $\mathrm{EC}_{50}: 1.29 \pm 0.34, \mathrm{n}=12$ open square and) respectively. ${ }^{*} p>0.05$.

Figure 4: Vascular hypersensitivity to PE following endothelium denudation.

Constriction abrasion (compare to intact IMA) had the least potassium contractile response (generated a force $<9.8 \mathrm{mN}$ ) indicating that there was substantial smooth muscle cell damaged during the denudation procedure. These were considered unresponsive tissues and further evaluation with PE or A23187 was not undertaken.
The mechanical shear abrasion method is similar in effect to the 'bubble passage' techniques for arterial injury used previously by Guyton et al. [17]. As anticipated, histological examination revealed a denuded endothelial lining and functional studies showed a loss of endothelium-dependent vasodilation as well as hyperconstrictor responses to $\mathrm{PE}$, using this denudation method. In contrast, IMA subjected to the surface abrasion technique resulted in incomplete endothelial denudation on histological examination and an intact endothelium-dependent vasodilator response to A23187. On the other hand, the constrictor abrasion method produced severe damage to the smooth muscle cell layer so that constrictor responses to vasopressor could not be evoked.

In contrast to these human IMA studies, endothelial denudation with surface abrasion and constrictor methods have been successfully employed in animal studies. Wang et al successfully used a sand paper polished cat whisker in surface abrasion method to denude the endothelium of foetal pulmonary resistance artery [18]. He obtained total endothelial removal as depicted by vascular hypersensitivity after endothelial removal. Lu et al used a specifically designed catheter in constriction abrasion method to successfully denude the artery of Wistar rat [16]. Other successful denudation methods employed in animal vascular reactivity studies include: gentle rubbing of the luminal surface of the vessel with wooden stick [8], syringe needle [9], stainless steel wire [10,11], forcept [12], blunt seeker [13], balloon catheter $[14,15]$ and intense vascular constriction upon a intravascular rod [16]. This clearly illustrates the differences between animal and human isolated vessel studies.

The difficulty in achieving effective endothelial denudation in isolated human vessels has been reported by other investigators. For example, $\mathrm{Lu}$ et al. applied mechanical surface abrasion techniques to denude IMA and subjected them to Vasoactive Intestinal Peptide (VIP) to evoke endothelium dependent relaxation and observed $20 \%$ relaxation to the VIP. This is consistent in our studies involving surface abrasion demonstrating that there is residual endothelial vasodilatory function in response to VIP [19]. A similar result was observed by Pagan et al. using urotensin II as a vasodilator after IMA denudation with a residual $20 \%$ endothelium-dependent relaxation response [20]. Thus although these studies reported IMA denudation by surface abrasion, the residual endothelium-dependent relaxation responses infer that an endothelium-dependent mechanism had not been completely excluded.

The human IMA is an outstanding conduit of choice for CABG. Unlike saphenous vein graft, which has a median patency of 7 years, more than $90 \%$ of IMA grafts are patent at 15 years [21]. This in part is attributable to its endothelial function. Moreover, despite CABG patients having established atherosclerotic disease and significant $\mathrm{CV}$ risk factors (contribute to endothelial dysfunction) all of the IMA segments demonstrated intact endothelial responses with little or no atherosclerotic plaque formation prior to the interventions.

The challenge of denuding the IMA is due to its unique structural and morphological arrangement compared to other vessels [22]. Structural and morphological analysis reveal that the media of the IMA is organized into two distinct layers: the internal muscular layer and an external layer with spirally oriented elastic lamellae that house the smooth muscle cells in between these layers [23]. The endothelial layer has fewer fenestrations and lower intercellular junction permeability [22], both of which contribute to its resilient nature to atherosclerotic plaque formation and provide greater endothelial attachment to the luminal surface. This later property limits endothelial denudation by 
Citation: Lamin V, Worthington M, Edwards J, Viana F, Stuklis R, et al. (2016) Endothelial Denudation of Isolated Human Internal Mammary Artery Segments. Cardiovasc Pharm Open Access 5: 180. doi:10.4172/2329-6607.1000180

the surface or constrictor abrasion methods, whereas the shear abrasion method is effective and superior to the other methods. Moreover, it has an additional theoretical advantage of keeping the vascular segment under a more physiologic condition during the denudation process and requires less skill to be successful.

\section{Conclusion}

In this systematic, comprehensive, controlled comparative study assessing both structural and functional endpoints of endothelial denudation techniques, we have demonstrated that the shear abrasion method is the optimal technique for human IMA segment endothelial denudation. This should be employed in future isolated human IMA vascular reactivity studies requiring endothelial denudation.

\section{Authors' contributions}

Victor Lamin designed and executed the experiments. Victor Lamin and John Beltrame wrote the manuscript. David Wilson revised the manuscript. Michael Worthington, James Edwards, Fabiano Viana and Robert Stuklis helped with the experimental design and data analysis. All authors read and approved the final version of the manuscript.

\section{Acknowledgement}

We thank Irene Stafford, Cardiology Research Unit for her assistance in data interpretation and other technical support in histological sample preparation.

\section{References}

1. Rajendran $P$, Rengarajan $T$, Thangavel J, Nishigaki $Y$, Sakthisekaran $D$, et al. (2013) The vascular endothelium and human diseases. Int J Biol Sci 9: 1057-1069.

2. Furchgott RF, Zawadzki JV (1980) The obligatory role of endothelial cells in the relaxation of arterial smooth muscle by acetylcholine. Nature 288: 373-376.

3. Urabe M, Kawasaki H, Takasaki K (1991) Effect of endothelium removal on the vasoconstrictor response to neuronally released 5-hydroxytryptamine and noradrenaline in the rat isolated mesenteric and femoral arteries. $\mathrm{Br} \mathrm{J}$ Pharmacol 102: 85-90.

4. Dora KA, Hinton JM, Walker SD, Garland CJ (2000) An indirect influence of phenylephrine on the release of endothelium-derived vasodilators in rat small mesenteric artery. Br J Pharmacol 129: 381-387.

5. Tesfamariam B, Halpern W, Osol G (1985) Effects of perfusion and endothelium on the reactivity of isolated resistance arteries. Blood Vessels 22: 301-305.

6. Gustafsson H, Mulvany MJ, Nilsson H (1993) Rhythmic contractions of isolated small arteries from rat: influence of the endothelium. Acta Physiol Scand 148: 153-163.

7. Osol G, Cipolla M, Knutson S (1989) A new method for mechanically denuding the endothelium of small (50-150 microns) arteries with a human hair. Blood Vessels 26: 320-324.

8. Borna C, Wang L, Gudbjartsson T, Karlsson L, Jern S, et al. (2003) Contractions in human coronary bypass vessels stimulated by extracellular nucleotides. Ann Thorac Surg 76: 50-57.
9. Tanaka N, Nakamura E, Ohkura M, Kuwabara M, Yamashita A, et al. (2008) Both 5-Hydroxytryptamine 5-HT2A and 5-HT1B receptors are involved in the vasoconstrictor response to $5-\mathrm{HT}$ in the human isolated internal thoracic artery. Clin Exp Pharmacol Physiol 35:836-840.

10. Wackenfors A, Ingemansson R, Malmsjö M (2003) Endothelin receptors in endothelium-denuded human coronary artery bypass grafts and coronary arteries. Ann Thorac Surg 75: 874-881.

11. Jovanović A, Grbović L, Tulić I (1994) Predominant role for nitric oxide in the relaxation induced by acetylcholine in human uterine artery. Hum Reprod 9 : 387-393.

12. Allen SP, Chester AH, Dashwood MR, Tadjkarimi S, Piper PJ, et al. (1994) Preferential vasoconstriction to cysteinyl leukotrienes in the human saphenous vein compared with the internal mammary artery. Implications for graft performance. Circulation 90: 515-524.

13. Wiley KE, Davenport AP (2002) Comparison of vasodilators in human internal mammary artery: ghrelin is a potent physiological antagonist of endothelin-1. $\mathrm{Br}$ J Pharmacol 136: 1146-1152.

14. Poppa V, Miyashiro JK, Corson MA, Berk BC (1998) Endothelial NO synthase is increased in regenerating endothelium after denuding injury of the rat aorta. Arterioscler Thromb Vasc Biol 18: 1312-1321.

15. Lamping KG, Marcus ML, Dole WP (1985) Removal of the endothelium potentiates canine large coronary artery constrictor responses to 5-hydroxytryptamine in vivo. Circ Res 57: 46-54.

16. Lu X, Guo X, Linares C, Kassab GS (2004) A new method to denude the endothelium without damage to media: structural, functional, and biomechanical validation. Am J Physiol Heart Circ Physiol 286: H1889-H1894.

17. Guyton JR, Dao DT, Lindsay KL (1984) Endothelial denudation and myointimal thickening in the rat carotid artery induced by the passage of bubbles. Exp Mol Pathol 40: 340-348.

18. Wang Y, Mercer-Connolly A, Lines L, Toyoda O, Coceani F (1994) Endotheliumdenuded pulmonary Resistance Arteries From the Fetal Lamb: Preparation and Response to Vasoactive Agents. J Pharmacol Toxicol Methods 32:85-91.

19. Luu TN, Chester AH, O'Neil GS, Tadjkarimi S, Pepper JR, et al. (1993) Different responses of the human gastroepiploic and internal mammary arteries to vasoactive peptides. Am J Physiol 264: H583-587.

20. Pagán R, Martínez A, Hernández M, Martínez M, García-Sacristán A, et al (2012) Endothelial and neuronal factors functionally involved in the modulation noradrenergic vasoconstriction in healthy pig internal mammary artery. Biochem Pharmacol 83: 882-892.

21. Buxton BF, Hayward PA, Newcomb AE, Moten S, Seevanayagam S, et al (2009) Choice of conduits for coronary artery bypass grafting: craft or science? Eur J Cardiothorac Surg 35: 658-670.

22. Otsuka F, Yahagi K, Sakakura K, Virmani R (2013) Why is the mammary artery so special and what protects it from atherosclerosis? Ann Cardiothorac Surg 2: 519-526.

23. Borović ML, Borović S, Perić M, Vuković P, Marinković J, et al. (2010) The internal thoracic artery as a transitional type of artery: a morphological and morphometric study. Histol Histopathol 25: 561-576.
Citation: Lamin V, Worthington M, Edwards J, Viana F, Stuklis R, et al. (2016) Endothelial Denudation of Isolated Human Internal Mammary Artery Segments. Cardiovasc Pharm Open Access 5: 180. doi:10.4172/2329-6607.1000180

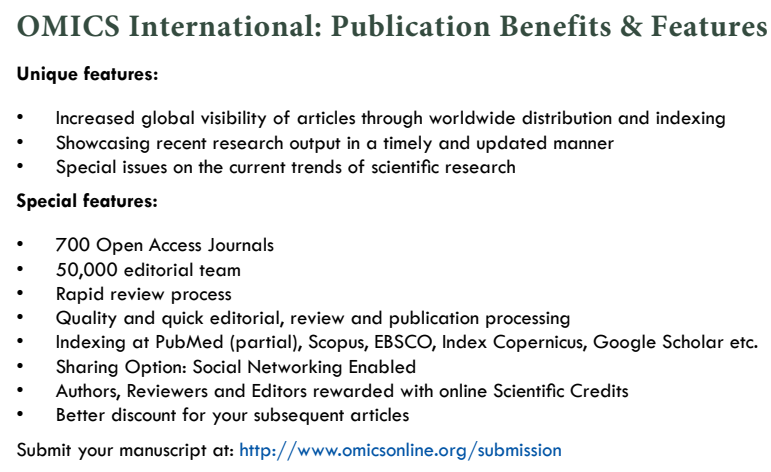

